
7

\title{
Mechanisms of human drug-induced anaphylaxis
}

\author{
Pierre Bruhns, $\mathrm{PhD}^{1,2}$ and Sylvie Chollet-Martin, $\mathrm{MD} \mathrm{PhD}^{3,4}$
}

\section{Authors' affiliations}

${ }^{1}$ Unit of Antibodies in Therapy and Pathology, Institut Pasteur, UMR 1222 INSERM, F-75015 Paris, France.

${ }^{2}$ DHU FIRE, Labex Inflamex, Université Paris Diderot Paris 7, F-75018 Paris, France.

${ }^{3}$ Department “Auto-immunité et Hypersensibilités », DMU BioGeM, APHP, Hôpital Bichat, F-75018 Paris, France.

4 «Inflammation, microbiome and immunosurveillance" INSERM UMR 996, Faculté de Pharmacie, Université Paris-Saclay, F-92290 Châtenay-Malabry, France.

Sources of funding: none of the sources of funding have an interest in the subject matter or materials discussed in the submitted manuscript

Correspondence to: Pierre Bruhns, Unit of Antibodies in Therapy and Pathology, Department of Immunology, Institut Pasteur, 25 rue du Docteur Roux, 75015 Paris, France. E-mail: bruhns@pasteur.fr; Sylvie Chollet-Martin, Inflammation Chimiokines et Immunopathologie, INSERM UMR S996, Faculté de Pharmacie, Université Paris-Saclay, 92290 Châtenay-Malabry, France. E-mail: sylvie.chollet$\underline{\text { martin@universite-paris-saclay.fr }}$ 
ABSTRACT

40 Drug-induced anaphylaxis is a hyperacute reaction affecting multiple organs that can be of fatal 41 consequence. Its incidence is increasing, consistent with a global increased sensitization to various 42 allergens and drugs in the population. Few risk factors and mechanisms have been identified from 43 human studies due to the rarity of anaphylactic events and their unpredictability. This systemic reaction 44 is caused by the rapid release of a large range of functionally diverse mediators, including histamine and 45 platelet-activating factor as the main drivers identified. Mechanisms defined from models of experimental anaphylaxis identify drug-specific antibodies of the $\operatorname{IgE}$ and $\operatorname{IgG}$ class that link the drug to antibody receptors on multiple cell types, causing their activation and mediator release. In the case of 48 drugs with peculiar chemical structures, antibodies may not be necessary as drug-binding receptors, like 49 mas-related G-protein coupled receptor member X2, have been identified. This review describes the 50 complex reaction leading to drug-induced anaphylaxis that can involve various antibody classes, various 51 cell types - including mast cells, neutrophils, platelets, basophils, macrophages and monocytes -, their 52 mediators and receptors that, importantly, can be implemented alone or in association to participate in the severity of the reaction. 


\section{KEY WORDS}

Anaphylaxis; drugs; IgE; IgG; MRGPRX2; platelet activating factor; histamine; serotonin; mast cells; basophils; neutrophils; platelets

59

60

61

62

63

64

65

66

67

68

69

70

\section{ABBREVIATIONS USED}

cPLA2: cytosolic phospholipase A2

CD32A: human activating IgG receptor Fc $\gamma$ RIIA

FceRI: high-affinity receptors for the Fc portion of $\operatorname{IgE}$

Fc $\gamma R$ : receptors for the Fc portion of IgG

Fc $\gamma R^{\text {null }}$ mice: mice deficient for Fc $\gamma$ RI, Fc $\gamma$ RIIB, Fc $\gamma$ RIII and Fc $\gamma$ RIV

$\mathrm{FcR} \gamma^{-/-}$mice: mice deficient for the FcR $\gamma$-chain, lacking all activating IgG and IgE receptors

FcRn: neonatal IgG recycling receptor

IL-4: interleukin-4

LuLISA: luciferase-linked immunosorbent assay

Mrgprb2: Mas-related G-protein coupled receptor member b2

MRGPRX2: Mas-related G-protein coupled receptor member X2

NETs: neutrophil extracellular traps

NMBA: neuromuscular blocking agents

NSAIDs: nonsteroidal anti-inflammatory drugs

PAF: platelet-activating factor

PAF-R: PAF-receptor

PAF-AH: PAF-acetyl hydrolase

PEG: polyethylene glycol 


\section{INTRODUCTION}

Anaphylaxis is a hyperacute reaction that can be of fatal consequence. It is a systemic reaction caused by the rapid and systemic release of a large range of functionally diverse mediators affecting multiple organs. These mediators typically induce urticaria, vasodilatation, increased vascular permeability and vascular leakage, edema and bronchoconstriction, leading to a drop in arterial pressure, tachycardia, bronchospasm and digestive troubles. Death can be caused by the resulting cardiac failure and/or asphyxia or pulmonary edema following major bronchospasm. Anaphylactic reactions cannot, in general, be foreseen. Due to their life-threatening nature, they represent an emergency situation for the medical staff.

The more recent publications describe a world incidence of anaphylaxis in humans between 50 and 112 episodes per 100000 person-years, and drug allergy mortality is estimated at $0.05-0.51$ per million people/year ${ }^{1}$. Interestingly, drug-induced anaphylaxis incidence is increasing, consistent with a global increased sensitization to various allergens in the population, including drugs ${ }^{2}$. Almost $60 \%$ of fatal anaphylaxis cases have been attributed to drugs ${ }^{3,4}$. Due to their increasing availability, the anaphylaxis to mAbs jumped at an average rate of $0.77 \%$ of total anaphylaxis reports per year in the

104 United States, from $2.00 \%$ in 1999 to $17.37 \%$ in 2019 ; it was the fastest increase observed among all 105 the drugs responsible for anaphylaxis ${ }^{5}$. Surprisingly, very different drugs - whether considering chemical nature or structure, size, target, mode of action, biodistribution - lead to anaphylactic events with similar symptoms and consequences. The most frequent culprit drugs are antibiotics (mostly penicillin and cephalosporins), nonsteroidal anti-inflammatory drugs (NSAIDs), injected radiocontrast agents (iodinated contrast media and gadolinium), antineoplastic drugs, therapeutic antibodies and neuromuscular blocking agents (NMBA) used during surgery ${ }^{3,4,6}$ Even more surprisingly, the size of

111 most of these compounds are 100-1,000 times smaller than "classical" allergens - linked to allergic 112 reactions to pollens, house dust mite, food allergens -, and due to this minimal size, these drugs would 113 rather qualify as haptens (Figure 1): antibiotics, e.g. Penicillin $334 \mathrm{Da}$; Ciprofloxacin $331 \mathrm{Da}$; NSIADs, 114 e.g. Ibuprofen 206 Da, Dicolfenac 296 Da; radiocontrast agents, e.g. Diatrizoate 613 Da; NMBA, e.g. 
116 systemically, could be interpreted as a common feature of drugs with anaphylactic potential.

117 Nevertheless, drugs of radically larger sizes, proteins of 20-180 kDa including therapeutic antibodies, 118 e.g. infliximab $149 \mathrm{kDa}$, cetuximab $152 \mathrm{kDa}$, or enzymes used for enzyme replacement therapy, e.g. 119 glucocerebrosidase $60 \mathrm{kDa}$, and polymers 200-35,000 kDa contained in drug preparations like 120 polyethylene glycol ${ }^{7,8}$ (Figure 1) that do not diffuse passively, are also reported to cause drug 121 anaphylaxis with similar kinetics. Adding to the complexity, the route of administration of the drug 122 responsible for anaphylaxis can be multiple: oral, infused, injected (intravenous, intradermal, 123 subcutaneous, intramuscular). Concerning the inhalation route, some cases have been reported in 124 asthmatic children using inhaled corticosteroids, probably related to milk protein traces ${ }^{9}$. This 125 variability in chemical nature, size, biodistribution of culprit drugs for anaphylactic events makes it 126 difficult to envision a single mechanism responsible for anaphylaxis induction.

127 Evidence of the mechanisms responsible for anaphylaxis from human studies is scarce due to 128 the rarity of anaphylaxis and its unpredictability, and thus of the very few prospective clinical studies 129 performed so far. Similarities between local allergic reactions (e.g. skin rashes, edema) and low-grade 130 systemic anaphylaxis has led to proposing mechanisms of allergic reactions as the basis of severe 131 anaphylactic reactions also without solid evidence to support them. Thus, clinical research in 132 anaphylaxis has mainly focused on accumulating evidence of an "allergic" mechanism, including 133 presence of certain mediators (e.g. histamine), enzymes (e.g. tryptase) and antibodies (e.g. IgE) 134 classically involved in local allergic reactions. If histamine, tryptase and allergen-specific IgE are rather 135 biomarkers than actual triggers of the anaphylactic reaction, which may be induced by other mechanisms 136 entirely, will be discussed herein. As an example, histamine is found at elevated levels during 137 anaphylactic reactions and proposed as the main mediator of anaphylaxis, but antihistamines do not 138 demonstrate efficacy on severe anaphylaxis symptoms. Below are summarized risk factors and evidence

139 from human studies to propose that anaphylaxis is an integration of diverse mechanisms leading to 140 systemic organ failure rather than, simply put, an extreme allergic reaction. 
Few risk factors have been identified that increase the risk of developing a drug-induced

144 anaphylactic event. Whereas sex remains a matter of debate with controversies on higher rates of drug-

145 induced anaphylaxis in women ${ }^{3,10}$, old age has been linked to both an increased risk of severe reactions

146 and a higher incidence ${ }^{11}$ with pre-existing cardiovascular morbidity being an important co-factor ${ }^{4}$.

147 Surprisingly, atopy and allergic status of the patients does not appear to be convincingly related to higher

148 risk of drug-induced anaphylaxis ${ }^{6}$, suggestive that different or additional mechanisms may be at play

149 in 'systemic' anaphylaxis compared to more 'local' allergic reactions. Nevertheless, patients with

150 mastocytosis, a disease characterized by the presence of high numbers of mast cells in various organs,

151 have a high occurrence of anaphylaxis ${ }^{12}$, suggesting of a role of mast cells - the crucial effector cell of

152 allergic reactions and inflammation ${ }^{13}-$ in anaphylaxis.

153 Mast cells are notorious for the ability to quickly release histamine, the major mediator

154 recognized in hypersensitivity reactions. Although antihistamines have not proven efficacious to prevent

155 or treat severe anaphylaxis, intravenous administration of histamine in volunteers has been shown to

156 reproduce most signs and symptoms of anaphylaxis, including cutaneous flushing, headache, airway

157 obstruction, and transient hemodynamic changes, mainly evidenced by systemic hypotension and

158 tachycardia ${ }^{14,15}$. Thus, histamine has the capacity to mediate the symptoms of anaphylaxis, but is clearly

159 not the sole mediator involved. Vadas et al indeed reported in their landmark study in 2008 that platelet-

160 activating factor (PAF) levels in serum were directly correlated, and the activity of its degrading enzyme,

161 PAF acetylhydrolase, inversely correlated, with the severity of anaphylaxis ${ }^{16}$. Their follow-up work ${ }^{17}$

162 reported that histamine, PAF and tryptase, the major enzyme of mast cell secretory granules already

163 identified as a biomarker for anaphylaxis ${ }^{18}$, were all detected in serum of patients that underwent

164 anaphylaxis of low- (grade 1), mild- (grade 2) and severe (grade 3) severity. However, serum

165 concentrations of PAF and tryptase, but not histamine, correlated with anaphylaxis severity ${ }^{17}$. PAF is

166 an extremely lipid mediator that can activate of a variety of cells that express the PAF-receptor (PAF-

167 R), including endothelium, smooth muscle, and myeloid cells including mast cells. Thus, PAF could

168 directly elicit the circulatory and respiratory symptoms of anaphylaxis while also eliciting the generation

169 of other mediators involved in anaphylaxis propagation and severity.Intracutaneous injection or

170 inhalation of PAF elicit symptoms resembling grade 1 anaphylaxis and bronchoconstriction , 
171 respectively, in human subjects ${ }^{19,20}$. Even though deficiencies in the enzyme degrading PAF, PAF-

172 acetylhydrolase (i.e. leading to high levels of PAF) have been correlated with respiratory deficiencies in

173 asthmatic children ${ }^{21}$, no study has linked it yet to anaphylaxis. Nevertheless PAF-acetylhydrolase

174 activity inversely correlates with anaphylaxis severity, and can be used as its marker ${ }^{16,22}$. In contrast to

175 PAF, mast cell tryptase is not thought to elicit rapid responses that contribute to immediate manifestation

176 of anaphylaxis, although its effects are only partially described ${ }^{23}$. Mast cells in the vicinity of an

177 activated mast cell releasing tryptase have been reported to become activated in turn and to release

178 histamine ${ }^{24}$. Tryptase is considered mainly a 'practical' marker of mast cell activation as it can be easily

179 detected in serum ${ }^{18}$. Altogether, these data suggest that among identified immediate mediators with

180 potency to be anaphylaxis inducers, PAF, rather than histamine, is the contributor of the more severe

181 forms of anaphylaxis (grade 3) and potentially of lethality (grade 4) when highly abundant systemically.

182 More explorations of anaphylactogenic mediators (e.g. leukotrienes, prostaglandins) in human drug-

183 induced anaphylaxis remains to be performed to understand fully the mechanisms leading to moderate

184 and severe symptoms, or even to lethality.

185

Until recently, only one pathway had been universally accepted as the mechanistic explanation

187 of anaphylaxis induction: the $\operatorname{IgE}$ antibody pathway. Antibodies of the $\operatorname{IgE}$ class are generated at in small quantities by B lymphocytes. Once produced, IgE antibodies have a very short half-life in circulation as they cannot be recycled by the $\mathrm{IgG}$ recycling receptor FcRn. Total IgE levels are thus only $50-200 \mathrm{ng} / \mathrm{mL}$ in healthy individuals but generally several fold higher in allergics, with patients having

191 allergen-specific IgE levels up to $200 \mathrm{ng} / \mathrm{mL}$, particularly those that experienced anaphylactic events ${ }^{25}$.

192 Direct evidence of the role of IgE in human anaphylaxis is based on transfer of purified human $\operatorname{IgE}$ in 193 the skin of human volunteers that transferred allergen reactivity ${ }^{26}$ and several clinical trials using the 194 anti-IgE therapeutic antibody omalizumab: one suggesting less spontaneous episodes of anaphylaxis in 195 patients with mastocytosis ${ }^{27}$, others proposing anti-IgE therapy as an adjunct therapy for allergic 196 desensitization, leading to fewer anaphylactic episodes ${ }^{28-30}$.

197 Although the precise conditions for human B cells to start producing an IgE remain speculative 198 and extrapolated from data obtained in animal models ${ }^{31}$, recent human studies found evidence that 
allergen-specific IgE B cells arise from mature B cells producing initially an allergen-specific IgG ${ }^{32}$. Although elusive, human circulating non-secreting IgE B cells, i.e. IgE memory B cells, as well as noncirculating IgE-secreting B cells, i.e. IgE plasma cells, have recently been identified (in extremely low numbers) in the blood and bone marrow, respectively, of allergic patients ${ }^{33,34}$. Indirectly supporting a role for these IgE-secreting cells located in the bone marrow in human anaphylaxis, bone marrow transplantation from allergic donors to non-allergic recipients has been reported in a few cases to transfer drug hypersensitivity, penicillin hypersensitivity for example (reviewed in ${ }^{35}$ ). Although several donor cell types in the allograft may contribute to the transfer of hypersensitivity, specific penicillin IgE could be detected 3 months after transplant, supporting the likely importance of graft-associated IgEproducing B cells ${ }^{36}$. This hypothesis is further supported by the observation that transplantation of livers from fatal anaphylaxis cases transferred food hypersensitivity (nuts or peanuts) to recipients with either detectable specific IgE or positive skin prick test (reviewed in ${ }^{35}$ ). Of note, IgE-producing B cells related to food allergy have been identified in the gut, and arise most probably from mature B cells producing 212 initially a food allergen-specific $\operatorname{IgA}{ }^{37}$. Wherever $\operatorname{IgE}$ is anatomically secreted - bone marrow, liver, gut 213 - it has the unique ability to 'sensitize' human mast cells in tissue but also human basophils in blood, 214 empowering them with the ability to react to a variety of specific targets, including allergens and drugs. This phenomenon, unique among antibody classes, relies on the IgE receptor FceRI that these cells express constitutively. FceRI is of such high-affinity that once bound an IgE remains on a mast cell for weeks ${ }^{38}$. Upon penetration of a drug/allergen in the body, it will bind to IgE-sensitized cells, provoke FceRI aggregation on their surface, leading to cell activation, degranulation and mediator release, including histamine, tryptase and PAF.

Although IgE may be responsible for many cases of anaphylaxis to drug or allergen, it may be undetectable in others ${ }^{39}$. In such cases, the terms "anaphylactoid reactions" (i.e. anaphylaxis-like reaction) or "idiopathic anaphylaxis" (i.e. anaphylaxis of unclear trigger) may be applied. IgG antibodies are proposed as causative agents, and can be detected in some patients who react to NMBA ${ }^{40}, \mathrm{PEG}^{41}$, 224 therapeutic antibodies and other drugs (reviewed in ${ }^{42}$ ). Although not proven, IgG antibodies could trigger activation of macrophages and other cells bearing Fc $\gamma$ receptors, either directly inducting 
anaphylaxis or acting in concert with IgE having the same specificity. Additionally, anaphylaxis-like

227 reactions to certain drugs may be caused by direct interaction with Mas-related G-protein coupled receptor member X2 (MRGPRX2), ${ }^{43,44}$ which is expressed at high level in primary human skin and synovial mast cells, but not in primary lung mast cells ${ }^{45}$. Many drugs capable of directly inducing histamine release can bind and activate MRGPRX2 ${ }^{46}$ (Figure 2).

\section{MECHANISMS IDENTIFED IN EXPERIMENTAL ANAPHYLAXIS}

Most animal models of systemic anaphylaxis are directly relevant to drug-induced anaphylaxis as they are based on the injection of a bolus of allergen/antigen/drug into a sensitized animal. Two main types of models are used. In passive systemic anaphylaxis, naive animals are directly injected with an anaphylactogenic mediator (e.g. histamine, PAF) or with antibodies thought to be responsible for anaphylaxis induction followed by a challenge with an allergen/antigen/drug in the next hours or days. In active systemic anaphylaxis, animals are exposed to low doses of an allergen/antigen/drug to induce an antibody response against that molecule followed by a challenge several weeks later. In the latter case, initial exposures can be performed in the presence or absence of an adjuvant. Surprisingly, models of active sensitization reveal that the presence or absence of adjuvant influences the principal mechanisms leading to anaphylaxis induction ${ }^{47-49}$. Thus, that each animal model of anaphylaxis, even each experimental protocol thereof, will draw a different picture of what pathways of anaphylaxis in 244 humans may be (discussed in ${ }^{42}$ ). Even though data may be considered conflicting between studies, animal models have provided an enlightened understanding of the multiple mechanisms at play that are, in our view, the current basis of human anaphylaxis exploration and dogma: antibodies of the IgE and/or

247 IgG class to the culprit drug triggering multiple cell types through activating antibody receptors, or mast cell activating receptors directly triggered by some drugs, notably Mas-related G-protein coupled receptor member b2 (Mrgprb2), the mouse ortholog of human MRGPRX2.

Passive systemic anaphylaxis. Injection of histamine or PAF in mice leads to symptoms 251 resembling systemic anaphylaxis that are dependent on the presence of histamine receptors or PAF 252 receptor (PAF-R), respectively ${ }^{50}$. Injection of allergen-specific IgE or allergen-specific IgG followed 253 by allergen challenge (generally intravenous injection) hours to days later provokes systemic, sometimes 
254 fatal, anaphylaxis that requires expression of FceRI or IgG receptors (FcyR), respectively (reviewed in $255^{47}$ and ${ }^{48}$ ). Both IgE and IgG receptors require cross-linking to trigger cell activation, implying that 256 multiple IgE or IgG molecules need to bind the same drug molecule, or that the drug has been haptenized 257 onto a carrier molecule to allow multimeric interactions. Among mouse IgG subclasses allergen-specific $258 \mathrm{IgG} 2 \mathrm{a}$ and $\mathrm{IgG} 2 \mathrm{~b}$ are potent inducers, whereas $\mathrm{IgG} 1$ is weak ${ }^{51}$, in line with its preferential binding to 259 inhibitory mouse $\mathrm{F} c \gamma \mathrm{R}^{52}$ and its rather anti-inflammatory role in mice ${ }^{53}$. Ciprofloxacin, an antibiotic of 260 the fluoroquinolone family, can induce antibody independent anaphylaxis in mice. Mice lacking 261 Mrgprb2 (the mouse orthologue of MRGPRX2) are protected from ciprofloxacin-induced anaphylaxis $262{ }^{44}$. As is the case for MRGPRX2 in humans, Mrgprb2 in mice is expressed almost exclusively on mast 263 cells and is since considered a direct target of several drugs belonging to fluoroquinolones, NMBA (e.g. 264 atracurium, rocuronium) chemical classes and cationic peptides ${ }^{43}$. A novel mouse model allowing for 265 the development of human mast cells expressing MRGPRX2 reported local mast cell degranulation after 266 exposure to contrast agents, but did not investigate systemic reactions ${ }^{54}$. Altogether passive models of 267 anaphylaxis validate antibody classes $\operatorname{IgE}$ and $\operatorname{IgG}$ and their receptors, Mrgprb2 and mediators histamine and PAF as potential inducers of anaphylaxis in simplified models (Figure 2), but are not able to rank 269 them or discriminate among them for their relevance in human anaphylaxis. Active systemic anaphylaxis. Mice sensitized with allergen in the presence of adjuvants show 271 detectable $\operatorname{IgE}$ and IgG specific for the allergen, and develop anaphylaxis upon allergen challenge 272 (intravenous, gavage) with severity increasing with higher doses of allergen. Surprisingly, IgE-deficient or FceRI-deficient mice were protected from some active anaphylaxis models, but not others, 274 demonstrating that the 'IgE pathway' is not necessary in some models active systemic anaphylaxis 275 (reviewed in ${ }^{48},{ }^{42}$ and ${ }^{55}$ ). In contrast, mice lacking all activating $\operatorname{IgG}$ and $\operatorname{IgE}$ receptors $\left(\mathrm{FcR} \gamma^{-/-}\right.$mice) 276 were resistant to anaphylaxis, as well as mice lacking only $\mathrm{IgG}$ receptors $\left(\mathrm{Fc} \gamma \mathrm{R}^{\mathrm{null}}\right)^{56-58}$. Transgenic 277 expression in $\mathrm{Fc} \gamma \mathrm{R}^{\text {null }}$ mice of a single ${ }^{59}$ or of multiple human $\mathrm{Fc} \gamma \mathrm{R}{ }^{57,58}$ restored anaphylaxis, 278 demonstrating the requirement of the 'IgG pathway' in severe active systemic anaphylaxis. Even though 279 convincing animal studies on the potential contribution of the complement system to anaphylaxis are 280 still lacking (discussed in ${ }^{42}$ ), some compounds trigger complement component C3a production leading 
to myeloid cell activation through their complement receptors and, thus, to PAF and histamine release generation (and, in the case of cPLA2, leukotriene and prostaglandin generation) had markedly reduced anaphylaxis symptoms ${ }^{50,56}$. PAF-R antagonists consistently strongly inhibited anaphylaxis symptoms and protected from lethality in different mouse models of active anaphylaxis, whereas antihistamines had moderate to negligible effects, unless in concert with PAF-R antagonists ${ }^{49,51,56,61,62}$. Depending on the active systemic anaphylaxis model and/or the mouse strain used, tissue-resident mast cells and macrophages, and circulating basophils, monocytes and neutrophils have all been convincingly reported to be main (reviewed in ${ }^{48},{ }^{42}$ and ${ }^{55}$ ). More recently platelets were added to this list through two independent reports using human activating IgG receptor Fc $\gamma$ RIIA (CD32A) transgenic mice, proposing that platelets release pathogenic serotonin in response to Fc $\gamma$ RIIA triggering on their surface by circulating IgG-antigen/allergen immune complexes (Figure 2) ${ }^{58,63}$ that form following exposure to high amounts of antigen/allergen as is mostly the case in drug anaphylaxis. The abundance and systemic distribution of platelets suggests a plausible role in anaphylaxis. Because humans and non-human primates, but not rodents, express FcyRIIA ${ }^{52}$, the potential contribution of platelets in anaphylaxis models may be missed in mice lacking transgenic expression of Fc $\gamma$ RIIA.

While animal studies suggest a diverse range of initiating pathways for anaphylaxis, demonstrating the contribution of each pathway in severe human anaphylaxis is challenging, since sampling of blood is typically undertaken after the reaction has occurred. Nevertheless, markers have been proposed to confirm the engagement of the IgE pathway (increase in interleukin-4 (IL-4) and soluble IL-4 receptor levels) and/or the IgG pathway (decrease in Fc $\gamma \mathrm{R}$ expression) ${ }^{64}$, which have been reported to occur simultaneously in a mouse model of fatal anaphylaxis ${ }^{61}$. Our group demonstrated the reduced Fc $\gamma R$ expression was a marker of the IgG pathway in passive and active mouse models of anaphylaxis ${ }^{51,57}$ and in our recent clinical study on NMBA-induced anaphylaxis (described in the next section) ${ }^{40}$. The diverse range of candidate effector cell types identified in animal studies makes their relative contribution difficult to comprehend in humans. The contributions from different cell types are 
likely influenced by cell numbers, their capacities for activation, and the abundance of mediators

309 generated per cell. Among circulating cells, platelets $(150,000-450,000 / \mu \mathrm{L})$ are $\sim 70, \sim 700$ and

$310 \sim 100,000$-fold more abundant than neutrophils $(2,500-6,000 / \mu \mathrm{L})$, monocytes $(200-600 / \mu \mathrm{L})$ and

311 basophils $(1-3 / \mu \mathrm{L})$. How these compare to mast cell and macrophage numbers is unclear as both cell

312 types reside in various human tissues in which they differentiate into different subpopulations expressing

313 different enzymes, receptors (including different IgG receptors and levels of MRGPRX2 for mast cells)

314 and mediators ${ }^{65,66}$. Skin mast cell densities in humans vary depending on the anatomical location ${ }^{67}$.

315 Considering numbers only, platelets and neutrophils would probably largely dominate over mast cells

316 and macrophages, whereas mast cells and basophils would likely be the dominant cell types activated

317 through IgE and MRGPRX2-dependent pathways. Considering the high levels of specific IgG necessary

318 for generating immune complexes with their target drug to trigger Fc $\gamma$ Rs, compared to few specific IgE-

319 bound FceRI on sensitized mast cells and basophils necessary to trigger their activation (Figure 2), $\operatorname{IgE}$

320 would largely dominate over $\operatorname{IgG}^{68}$. These considerations apply even more in anaphylaxis to ingested

321 drugs/antigens that require the compound to reach circulation, as only as small fraction of the ingested

322 compound is absorbed ${ }^{69,70}$. Solving this equation is next to impossible, but informs clinicians of the

323 possibility that one, two or even three different pathways, involving different antibody classes (or none),

324 different receptors and different cells types in circulation and tissue resident, may be at play

325 simultaneously in a drug-induced severe anaphylactic reaction. This next section will propose a

326 clinician's view on drug-induced anaphylaxis, taking NMBA-hypersensitivity as an example.

NMBA-INDUCED ANAPHYLAXIS EXEMPLFLIES MULTIPLE MECHANISMS AT PLAY

As emphasized above with the animal models, the possible mechanisms leading to anaphylaxis

330 in human begin to be better understood, as more and more actors are evidenced at the cellular or soluble

331 levels that can interact and define complex endotypes. The example we chose to describe in this section

332 in detail is NMBA-induced anaphylaxis during the perioperative period as it may be representative of drug-induced severe anaphylaxis implicating several pathways that synergize to increase severity. 
335 of 1 in 10,000-20,000 anesthesia procedures. For the 2011-2012 period, in 714 patients who experienced 336 perioperative anaphylaxis in France, the most common cause was NMBA administration $(60 \%)^{71}$. The 337 classical IgE-dependent mechanism that involves basophil and mast cell degranulation has been clearly documented in various studies for several years, mainly using the morphine quaternary ammonium (QA) as a surrogate epitope of antibody responses to NMBA, even if one can be critical on this laboratory

340 reagent, the only one commercially available so far ${ }^{72}$. Interestingly, the historical hapten concept has

341 been recently revisited by its author, Dr Werner J Pichler, who postulates now that in the minutes

342 following the re-exposure to a drug, a massive mast cell degranulation occurs in response to IgE cross-

343 linking by non-covalent drug-carrier complex called "fake antigen" ${ }^{73}$. However, concerning NMBAs, 344 the absence of any sign of IgE-dependent immune activation despite evident clinical anaphylaxis in 10$34520 \%$ of patients led us to test the hypothesis of an IgG-induced neutrophil activation, as we previously 346 described in mouse models ${ }^{56}$.

347 We prospectively conducted a multicenter study of 86 patients with suspected anaphylaxis to 348 NMBAs during general anesthesia and 86 matched controls (age, sex, drug, type of surgery) ${ }^{40}$. We 349 found that circulating anti-QA IgE was undetectable in a large percentage of the patients, whereas anti350 QA IgG levels were significantly increased as compared to matched controls. Moreover, both anti-QA $351 \mathrm{IgE}$ and $\operatorname{IgG}$ levels correlated with anaphylaxis severity. We then found that down-regulation of Fc $\gamma \mathrm{Rs}$ 352 (CD32A, CD16) at the neutrophil surface was also associated with reaction severity, suggesting that anti-QA specific IgG formed immune complexes with NMBA to rapidly activate circulating neutrophils.

354 This was further supported by increased neutrophil expression of CD11b and CD66b, elevated 355 circulating levels of degranulated elastase and decreased PAF-acetyl hydrolase (PAF-AH) activity 356 related to PAF secretion. Moreover, high levels of neutrophil extracellular traps (NETs), detected as 357 DNA-myeloperoxidase complexes, were found in severe patients as compared to mild patients and to 358 controls. Altogether, using a large panel of neutrophil activation markers, we could confirm that, in 359 human, an IgG-dependent neutrophil activation occurs during NMBA anaphylaxis with, or 360 independently of, IgE-dependent mast cell/basophil activation (Figure 3). 
362 CD32A-expressing platelets can induce anaphylaxis in animal models, platelet activation in the same 363 patient cohort suffering from NMBA anaphylaxis was associated with anaphylaxis severity and was 364 accompanied by a reduction in circulating platelet numbers ${ }^{58}$. In order to better document IgG-mediated 365 mechanisms in anaphylaxis, we isolated rocuronium-specific IgG from one patient and found that they 366 could form immune complexes with rocuronium that could in turn activate neutrophils isolated from 367 healthy controls, as evidenced by the activation of oxidative burst and NET release (Figure 3). These 368 results reconcile clinical and experimental data on the role of $\operatorname{IgE}$ and $\operatorname{IgG}$ during anaphylaxis and can 369 modify our biological diagnostic approaches to NMBA-induced anaphylaxis, even if skin tests remain 370 major tools for IgE-mediated reactions. Indeed, we can now suggest to implement the classical 371 biological evaluation of suspected NMBA anaphylaxis ${ }^{74,75}$ by exploring both IgE- basophil and IgGneutrophil pathways.

374 (as a surrogate epitope of NMBAs) and against each independent NMBA (rocuronium, atracurium, 375 suxamethonium) can be made using commercial (ImmunoCAP, ThermoFisher) or home-made 376 techniques, but the specificity is not optimal, false positivity and numerous cross-reactivities are 377 observed ${ }^{76}$. The calculation of specific to total IgE ratio did not improve the biological diagnosis of rocuronium allergy ${ }^{77}$. Sensitization to NMBAs might originate from exposure to other drugs or 379 compounds that contain also a QA epitope, like pholcodine (a morphine derivative contained in anti380 cough medications): indeed, anti-pholcodine IgE can be detected in NMBA hypersensitive patients ${ }^{78}$. 381 Altogether these recent studies emphasize the difficulties of correctly quantifying the circulating anti382 NMBA IgEs. New methods are needed and we can assume that the recent luciferase-linked 383 immunosorbent assay (Lu-LISA) that demonstrated 10-100-fold better sensitivity than ImmunoCAP for 384 peanut allergen-specific IgE could be adapted to other allergens and drugs including NMBA-specific 385 IgE detection, providing perhaps enhanced sensitivity and specificity ${ }^{79}$. In addition to anti-NMBA 386 specific IgE, we now recommend, using similar techniques, to assay anti-NMBA specific IgG to 387 increase the understanding of our clinical findings reported in $2019^{40}$. 
Assays to detect soluble mediators can be used to invoke mechanisms involved in anaphylaxis.

389 Histamine and tryptase measurements, routinely used to confirm an anaphylactic reaction, reflect the 390 activation of mast cells and, in the case of histamine, basophils. An elevated level of serum tryptase 391 remains one of the very best markers of anaphylaxis. However, the level of tryptase at baseline (after resolution of the anaphylactic reaction) is required to calculate the acute tryptase levels using the 393 following algorithm: tryptase levels are acute if $>[1.2 \times$ baseline tryptase $]+2 \mu \mathrm{g} / \mathrm{L}^{80}$. Baseline levels of 394 tryptase are elevated in patients with mastocytosis (reflecting increased mast cell burden), and are associated with an increased risk of recurrent perioperative anaphylaxis ${ }^{81}$. As noted previously, human mast cells strongly express MRGPRX2 (which is also expressed more weakly by basophils in humans ${ }^{82}$ ). MRGPRX2 can directly bind a number of drugs leading to mast cell activation and mediator release such as tryptase ${ }^{44}$, meaning that elevated circulating tryptase levels at the initial phase of anaphylaxis can thus been generated by IgE- or MRGPRX2-dependent mast cell activation, or both. Initially the list 400 of drugs activating MRGPRX2 included NMBAs atracurium and rocuronium among others, but 401 conflicting results have placed this assumption under debate ${ }^{83,84}$. The ability and importance of 402 rocuronium-induced MRGPRX2 activation is under evaluation, investigating effects of MRGPRX2 403 mutations ${ }^{85,86}$. diagnosis. The basophil activation test (BAT) is a useful tool to document NMBA anaphylaxis ${ }^{87}$ that needs to be performed 4-6 weeks after the episode. This flow cytometry-based ex vivo assay can be adapted to other NMBAs ${ }^{88}$. The versatility of BAT testing may make it an increasingly utilized tool in 408 the diagnosis of NMBA-induced anaphylaxis. Additionally, elastase levels (using ELISA) and DNAMPO levels (markers of increased netosis) may be useful for detecting neutrophil activation during anaphylaxis (Figure 3$)^{89}$. We can propose that a simple phenotypic study such as CD11b and CD66b expression, monitored over the course of a clinical reaction in parallel with tryptase, can document a

412 potential specific anti-NMBA IgG-induced neutrophil activation at the time of the reaction in case of 413 the presence of specific IgG. 

extensively documented and diagnosed by adequate biological tools, 2) a complex reaction that can involve various cell types, mediators, receptors and intracellular pathways that can be activated alone or in association (Figure 2); NMBA-induced anaphylaxis being an ideal example. MRGPRX2, exemplified by the role of contact system via factor XII activation and bradykinin release in some penicillin-induced anaphylaxis ${ }^{90}$, or after heparin injection and severe hypotension due to oversulfated chondroitin sulfate contamination ${ }^{91}$. Explorations outside of basophil activation, i.e. neutrophil, platelet and monocyte activation, and of anti-drug $\operatorname{IgE}$, i.e. presence of anti-drug $\operatorname{IgG}{ }^{40,41 \text {, }}$ ${ }^{92}$, should increase in clinical research to improve our understanding of anaphylaxis and define markers for its endotypes. Because many anaphylactic reactions to drugs happen at first exposure, identifying potential cross-reactivities is of major importance to discourage use of some drugs in potentially susceptible patients; hypersensitivity to the oligosaccharide alpha-gal as a consequence of tick bites leading to cetuximab anaphylaxis is a good example ${ }^{93}$. In contrast, sensitization to some cereal and peach allergens (Lipid Transfer Protein) are high risk factors to NSAIDs anaphylaxis, without any crossreactivity identified ${ }^{94}$.

The first line treatment of any type of anaphylaxis, whatever the mechanism, is adrenaline (epinephrine). As far as therapeutic tools are concerned, the avoidance of the drug is the only efficient action when possible. If not possible, anaphylaxis might be prevented by pre-treating patients with the anti-IgE antibody omalizumab as it is known to be useful in drug desensitization ${ }^{95}$. Anti-drug therapy to prevent IgE engagement might also be considered: allergen desensitization by anti-cat allergen antibody therapy has indeed been reported already ${ }^{96}$, and might be transposed to drugs ${ }^{97}$. Anti-drug therapy to capture the drug remains a poorly explored avenue to remove quickly the culprit drug and thereby arrest the ongoing anaphylactic reaction: attempts have been described in NMBA-induced anaphylaxis ${ }^{98}$ due to the existence of a rocuronium and vecuronium capture reagent, sugammadex, but remains debated ${ }^{99-101}$. Unfortunately, a significant number of (IgE-mediated) sugammadex-induced 442 anaphylactic reactions have been described ${ }^{102-104}$, making this particular therapeutic compound non 443 ideal to explore drug capture as a therapy for drug-induced anaphylaxis. Novel anti-drug therapies need 
444 to be developed to understand the potential of drug capture to reduce anaphylaxis severity or even to 445 stop an ongoing anaphylactic reaction.

446 
448 This work was supported by the Institut Pasteur, the Institut National de la Santé et de la 449 Recherche Médicale (INSERM) and by the European Research Council (ERC)-Seventh 450 Frame-work Program (ERC-2013-CoG 616050) and a Contrat Local d'Interface to PB of the 451 Assistance Publique des Hôpitaux de Paris (AP-HP).

452 
1. Cardona V, Ansotegui IJ, Ebisawa M, El-Gamal Y, Fernandez Rivas M, Fineman S, et al. World allergy organization anaphylaxis guidance 2020. World Allergy Organ J 2020; 13:100472.

2. Tanno LK, Demoly P. Epidemiology of anaphylaxis. Curr Opin Allergy Clin Immunol 2021.

3. Jerschow E, Lin RY, Scaperotti MM, McGinn AP. Fatal anaphylaxis in the United States, 1999-2010: temporal patterns and demographic associations. J Allergy Clin Immunol 2014; 134:1318-28 e7.

4. Turner PJ, Jerschow E, Umasunthar T, Lin R, Campbell DE, Boyle RJ. Fatal Anaphylaxis: Mortality Rate and Risk Factors. J Allergy Clin Immunol Pract 2017; 5:1169-78.

5. Yu RJ, Krantz MS, Phillips EJ, Stone CA, Jr. Emerging Causes of Drug-Induced Anaphylaxis: A Review of Anaphylaxis-Associated Reports in the FDA Adverse Event Reporting System (FAERS). J Allergy Clin Immunol Pract 2020.

6. Kuruvilla M, Khan DA. Anaphylaxis to drugs. Immunol Allergy Clin North Am 2015; 35:303-19.

7. Sellaturay P, Nasser S, Ewan P. Polyethylene Glycol-Induced Systemic Allergic Reactions (Anaphylaxis). J Allergy Clin Immunol Pract 2020.

8. Wenande E, Garvey LH. Immediate-type hypersensitivity to polyethylene glycols: a review. Clin Exp Allergy 2016; 46:907-22.

9. Savvatianos S, Giavi S, Stefanaki E, Siragakis G, Manousakis E, Papadopoulos NG. Cow's milk allergy as a cause of anaphylaxis to systemic corticosteroids. Allergy 2011; 66:9835.

10. Banerji A, Rudders S, Clark S, Wei W, Long AA, Camargo CA, Jr. Retrospective study of drug-induced anaphylaxis treated in the emergency department or hospital: patient characteristics, management, and 1-year follow-up. J Allergy Clin Immunol Pract 2014; 2:46-51.

11. Clark S, Wei W, Rudders SA, Camargo CA, Jr. Risk factors for severe anaphylaxis in patients receiving anaphylaxis treatment in US emergency departments and hospitals. J Allergy Clin Immunol 2014; 134:1125-30.

12. Schuch A, Brockow K. Mastocytosis and Anaphylaxis. Immunol Allergy Clin North Am 2017; 37:153-64.

13. Bischoff SC. Role of mast cells in allergic and non-allergic immune responses: comparison of human and murine data. Nat Rev Immunol 2007; 7:93-104.

14. Vigorito C, Russo P, Picotti GB, Chiariello M, Poto S, Marone G. Cardiovascular effects of histamine infusion in man. J Cardiovasc Pharmacol 1983; 5:531-7.

15. Kaliner M, Sigler R, Summers R, Shelhamer JH. Effects of infused histamine: analysis of the effects of $\mathrm{H}-1$ and $\mathrm{H}-2$ histamine receptor antagonists on cardiovascular and pulmonary responses. J Allergy Clin Immunol 1981; 68:365-71.

16. Vadas P, Gold M, Perelman B, Liss GM, Lack G, Blyth T, et al. Platelet-activating factor, PAF acetylhydrolase, and severe anaphylaxis. N Engl J Med 2008; 358:28-35.

17. Vadas P, Perelman B, Liss G. Platelet-activating factor, histamine, and tryptase levels in human anaphylaxis. J Allergy Clin Immunol 2013; 131:144-9. 
18. Schwartz LB, Metcalfe DD, Miller JS, Earl H, Sullivan T. Tryptase levels as an indicator of mast-cell activation in systemic anaphylaxis and mastocytosis. N Engl J Med 1987; 316:1622-6.

19. Basran GS, Page CP, Paul W, Morley J. Platelet-activating factor: a possible mediator of the dual response to allergen? Clin Allergy 1984; 14:75-9.

20. Cuss FM, Dixon CM, Barnes PJ. Effects of inhaled platelet activating factor on pulmonary function and bronchial responsiveness in man. Lancet 1986; 2:189-92.

21. Miwa M, Miyake T, Yamanaka T, Sugatani J, Suzuki Y, Sakata S, et al. Characterization of serum platelet-activating factor (PAF) acetylhydrolase. Correlation between deficiency of serum PAF acetylhydrolase and respiratory symptoms in asthmatic children. J Clin Invest 1988; 82:1983-91.

22. Pravettoni V, Piantanida M, Primavesi L, Forti S, Pastorello EA. Basal platelet-activating factor acetylhydrolase: prognostic marker of severe Hymenoptera venom anaphylaxis. J Allergy Clin Immunol 2014; 133:1218-20.

23. Payne V, Kam PC. Mast cell tryptase: a review of its physiology and clinical significance. Anaesthesia 2004; 59:695-703.

24. He S, Gaca MD, Walls AF. A role for tryptase in the activation of human mast cells: modulation of histamine release by tryptase and inhibitors of tryptase. J Pharmacol Exp Ther 1998; 286:289-97.

25. Platts-Mills TAE, Schuyler AJ, Erwin EA, Commins SP, Woodfolk JA. IgE in the diagnosis and treatment of allergic disease. J Allergy Clin Immunol 2016; 137:1662-70.

26. Ishizaka K, Ishizaka T, Richter M. Effect of reduction and alkylation on allergencombining properties of reaginic antibody. J Allergy 1966; 37:135-44.

27. Carter MC, Robyn JA, Bressler PB, Walker JC, Shapiro GG, Metcalfe DD. Omalizumab for the treatment of unprovoked anaphylaxis in patients with systemic mastocytosis. J Allergy Clin Immunol 2007; 119:1550-1.

28. Nadeau KC, Kohli A, lyengar S, DeKruyff RH, Umetsu DT. Oral immunotherapy and antiIgE antibody-adjunctive treatment for food allergy. Immunol Allergy Clin North Am 2012; 32:111-33.

29. Boni E, Incorvaia C, Mauro M. Dose-dependence of protection from systemic reactions to venom immunotherapy by omalizumab. Clin Mol Allergy 2016; 14:14.

30. MacGinnitie AJ, Rachid R, Gragg H, Little SV, Lakin P, Cianferoni A, et al. Omalizumab facilitates rapid oral desensitization for peanut allergy. J Allergy Clin Immunol 2017; 139:873-81 e8.

31. Davies JM, Platts-Mills TA, Aalberse RC. The enigma of IgE+ B-cell memory in human subjects. J Allergy Clin Immunol 2013; 131:972-6.

32. Looney TJ, Lee JY, Roskin KM, Hoh RA, King J, Glanville J, et al. Human B-cell isotype switching origins of IgE. J Allergy Clin Immunol 2016; 137:579-86 e7.

33. Croote D, Darmanis S, Nadeau KC, Quake SR. High-affinity allergen-specific human antibodies cloned from single IgE B cell transcriptomes. Science 2018; 362:1306-9.

34. Asrat S, Kaur N, Liu X, Ben LH, Kajimura D, Murphy AJ, et al. Chronic allergen exposure drives accumulation of long-lived IgE plasma cells in the bone marrow, giving rise to serological memory. Sci Immunol 2020; 5.

35. Khan F, Hallstrand TS, Geddes MN, Henderson WR, Jr., Storek J. Is allergic disease curable or transferable with allogeneic hematopoietic cell transplantation? Blood 2009; 113:279-90. 
36. Walker SA, Riches PG, Wild G, Ward AM, Shaw PJ, Desai S, et al. Total and allergenspecific IgE in relation to allergic response pattern following bone marrow transplantation. Clin Exp Immunol 1986; 66:633-9.

37. Hoh RA, Joshi SA, Lee JY, Martin BA, Varma S, Kwok S, et al. Origins and clonal convergence of gastrointestinal $\operatorname{IgE}(+) \mathrm{B}$ cells in human peanut allergy. Sci Immunol 2020; 5.

38. Kinet JP. The high-affinity IgE receptor (Fc epsilon RI): from physiology to pathology. Annu Rev Immunol 1999; 17:931-72.

39. Laroche D, Chollet-Martin S, Leturgie P, Malzac L, Vergnaud MC, Neukirch C, et al. Evaluation of a new routine diagnostic test for immunoglobulin $E$ sensitization to neuromuscular blocking agents. Anesthesiology 2011; 114:91-7.

40. Jonsson F, de Chaisemartin L, Granger V, Gouel-Cheron A, Gillis CM, Zhu Q, et al. An IgG-induced neutrophil activation pathway contributes to human drug-induced anaphylaxis. Sci Transl Med 2019; 11.

41. Zhou ZH, Stone CA, Jr., Jakubovic B, Phillips EJ, Sussman G, Park J, et al. Anti-PEG IgE in anaphylaxis associated with polyethylene glycol. J Allergy Clin Immunol Pract 2020.

42. Finkelman FD, Khodoun MV, Strait R. Human IgE-independent systemic anaphylaxis. J Allergy Clin Immunol 2016; 137:1674-80.

43. Tatemoto K, Nozaki Y, Tsuda R, Konno S, Tomura K, Furuno M, et al. Immunoglobulin E-independent activation of mast cell is mediated by Mrg receptors. Biochem Biophys Res Commun 2006; 349:1322-8.

44. McNeil BD, Pundir P, Meeker S, Han L, Undem BJ, Kulka M, et al. Identification of a mast-cell-specific receptor crucial for pseudo-allergic drug reactions. Nature 2015; 519:237-41.

45. Varricchi G, Pecoraro A, Loffredo S, Poto R, Rivellese F, Genovese A, et al. Heterogeneity of Human Mast Cells With Respect to MRGPRX2 Receptor Expression and Function. Front Cell Neurosci 2019; 13:299.

46. Lagunoff D, Martin TW, Read G. Agents that release histamine from mast cells. Annu Rev Pharmacol Toxicol 1983; 23:331-51.

47. Finkelman FD. Anaphylaxis: lessons from mouse models. J Allergy Clin Immunol 2007; 120:506-15; quiz 16-7.

48. Gillis CM, Gouel-Chéron A, Bruhns P. Anaphylaxis (Immediate Hypersensitivity): From Old to New Mechanisms. Encyclopedia of Inflammatory Diseases 2015.

49. Balbino B, Sibilano R, Starkl P, Marichal T, Gaudenzio N, Karasuyama H, et al. Pathways of immediate hypothermia and leukocyte infiltration in an adjuvant-free mouse model of anaphylaxis. J Allergy Clin Immunol 2017; 139:584-96 e10.

50. Ishii S, Kuwaki T, Nagase T, Maki K, Tashiro F, Sunaga S, et al. Impaired anaphylactic responses with intact sensitivity to endotoxin in mice lacking a platelet-activating factor receptor. J Exp Med 1998; 187:1779-88.

51. Beutier H, Gillis CM, lannascoli B, Godon O, England P, Sibilano R, et al. IgG subclasses determine pathways of anaphylaxis in mice. J Allergy Clin Immunol 2017; 139:269-80 e7.

52. Bruhns P. Properties of mouse and human IgG receptors and their contribution to disease models. Blood 2012; 119:5640-9.

53. Strait RT, Posgai MT, Mahler A, Barasa N, Jacob CO, Kohl J, et al. IgG1 protects against renal disease in a mouse model of cryoglobulinaemia. Nature 2015; 517:501-4. 
54. Mencarelli A, Gunawan M, Yong KSM, Bist P, Tan WWS, Tan SY, et al. A humanized mouse model to study mast cells mediated cutaneous adverse drug reactions. J Leukoc Biol 2020; 107:797-807.

55. Reber LL, Hernandez JD, Galli SJ. The pathophysiology of anaphylaxis. J Allergy Clin Immunol 2017; 140:335-48.

56. Jönsson F, Mancardi DA, Kita $\mathrm{Y}$, Karasuyama $\mathrm{H}$, lannascoli B, Van Rooijen $\mathrm{N}$, et al. Mouse and human neutrophils induce anaphylaxis. J Clin Invest 2011; 121:1484-96.

57. Gillis CM, Jonsson F, Mancardi DA, Tu N, Beutier H, Van Rooijen N, et al. Mechanisms of anaphylaxis in human low-affinity IgG receptor locus knock-in mice. J Allergy Clin Immunol 2017; 139:1253-65 e14.

58. Beutier $\mathrm{H}$, Hechler $\mathrm{B}$, Godon $\mathrm{O}$, Wang $\mathrm{Y}$, Gillis CM, de Chaisemartin L, et al. Platelets expressing IgG receptor FcgammaRIIA/CD32A determine the severity of experimental anaphylaxis. Sci Immunol 2018; 3.

59. Jönsson F, Mancardi DA, Zhao W, Kita $Y$, lannascoli $B$, Khun $H$, et al. Human FcgammaRIIA induces anaphylactic and allergic reactions. Blood 2012; 119:2533-44.

60. Khodoun M, Strait R, Orekov T, Hogan S, Karasuyama H, Herbert DR, et al. Peanuts can contribute to anaphylactic shock by activating complement. J Allergy Clin Immunol 2009; 123:342-51.

61. Liu E, Moriyama H, Abiru N, Miao D, Yu L, Taylor RM, et al. Anti-peptide autoantibodies and fatal anaphylaxis in NOD mice in response to insulin self-peptides B:9-23 and B:1323. J Clin Invest 2002; 110:1021-7.

62. Arias K, Baig M, Colangelo M, Chu D, Walker T, Goncharova S, et al. Concurrent blockade of platelet-activating factor and histamine prevents life-threatening peanutinduced anaphylactic reactions. J Allergy Clin Immunol 2009; 124:307-14, 14 e1-2.

63. Cloutier N, Allaeys I, Marcoux G, Machlus KR, Mailhot B, Zufferey A, et al. Platelets release pathogenic serotonin and return to circulation after immune complexmediated sequestration. Proc Natl Acad Sci U S A 2018; 115:E1550-E9.

64. Khodoun MV, Strait R, Armstrong L, Yanase N, Finkelman FD. Identification of markers that distinguish IgE- from IgG-mediated anaphylaxis. Proc Natl Acad Sci U S A 2011; 108:12413-8.

65. Kalesnikoff J, Galli SJ. New developments in mast cell biology. Nat Immunol 2008; 9:1215-23.

66. Epelman S, Lavine KJ, Randolph GJ. Origin and functions of tissue macrophages. Immunity 2014; 41:21-35.

67. Janssens AS, Heide R, den Hollander JC, Mulder PG, Tank B, Oranje AP. Mast cell distribution in normal adult skin. J Clin Pathol 2005; 58:285-9.

68. Strait RT, Morris SC, Finkelman FD. IgG-blocking antibodies inhibit IgE-mediated anaphylaxis in vivo through both antigen interception and Fc gamma RIlb cross-linking. J Clin Invest 2006; 116:833-41.

69. Strait RT, Mahler A, Hogan S, Khodoun M, Shibuya A, Finkelman FD. Ingested allergens must be absorbed systemically to induce systemic anaphylaxis. J Allergy Clin Immunol 2011; 127:982-9 e1.

70. Kucuk ZY, Strait R, Khodoun MV, Mahler A, Hogan S, Finkelman FD. Induction and suppression of allergic diarrhea and systemic anaphylaxis in a murine model of food allergy. J Allergy Clin Immunol 2012; 129:1343-8. 
71. Tacquard C, Collange O, Gomis P, Malinovsky JM, Petitpain N, Demoly P, et al. Anaesthetic hypersensitivity reactions in France between 2011 and 2012: the 10th GERAP epidemiologic survey. Acta Anaesthesiol Scand 2017; 61:290-9.

72. Baldo BA, Fisher MM. Substituted ammonium ions as allergenic determinants in drug allergy. Nature 1983; 306:262-4.

73. Pichler WJ. Anaphylaxis to drugs: Overcoming mast cell unresponsiveness by fake antigens. Allergy 2020.

74. Ansotegui IJ, Melioli G, Canonica GW, Caraballo L, Villa E, Ebisawa M, et al. IgE allergy diagnostics and other relevant tests in allergy, a World Allergy Organization position paper. World Allergy Organ J 2020; 13:100080.

75. Broyles AD, Banerji A, Barmettler S, Biggs CM, Blumenthal K, Brennan PJ, et al. Practical Guidance for the Evaluation and Management of Drug Hypersensitivity: Specific Drugs. J Allergy Clin Immunol Pract 2020; 8:S16-S116.

76. van der Poorten MM, Van Gasse AL, Hagendorens MM, Faber MA, De Puysseleyr L, Elst $\mathrm{J}$, et al. Serum specific IgE antibodies in immediate drug hypersensitivity. Clin Chim Acta 2020; 504:119-24.

77. Van Der Poorten MM, Molina-Molina G, Van Gasse AL, Hagendorens MM, Faber MA, De Puysseleyr L, et al. Application of specific-to-total IgE ratio does not benefit diagnostic performance of serologic testing for rocuronium allergy. Br J Anaesth 2020; 125:e443-e6.

78. Anderson J, Green S, Capon M, Krupowicz B, Li J, Fulton R, et al. Measurement of pholcodine-specific IgE in addition to morphine-specific IgE improves investigation of neuromuscular blocking agent anaphylaxis. Br J Anaesth 2020; 125:e450-e2.

79. Goyard S, Balbino B, Chinthrajah RS, Lyu SC, Janin YL, Bruhns P, et al. A highly sensitive bioluminescent method for measuring allergen-specific IgE in microliter samples. Allergy 2020.

80. Vitte J, Amadei L, Gouitaa M, Mezouar S, Zieleskiewicz L, Albanese J, et al. Paired acutebaseline serum tryptase levels in perioperative anaphylaxis: An observational study. Allergy 2019; 74:1157-65.

81. Banerji A, Bhattacharya G, Huebner E, Fu X, Camargo CA, Jr., Guyer A, et al. Perioperative Allergic Reactions: Allergy Assessment and Subsequent Anesthesia. J Allergy Clin Immunol Pract 2020.

82. Elst J, Sabato V, Hagendorens MM, van Houdt M, Faber MA, Bridts $\mathrm{CH}$, et al. Measurement and Functional Analysis of the Mas-Related G Protein-Coupled Receptor MRGPRX2 on Human Mast Cells and Basophils. Methods Mol Biol 2020; 2163:219-26.

83. Lansu K, Karpiak J, Liu J, Huang XP, McCorvy JD, Kroeze WK, et al. In silico design of novel probes for the atypical opioid receptor MRGPRX2. Nat Chem Biol 2017; 13:52936.

84. Ebo DG, Van der Poorten ML, Elst J, Van Gasse AL, Mertens C, Bridts C, et al. Immunoglobulin $\mathrm{E}$ cross-linking or MRGPRX2 activation: clinical insights from rocuronium hypersensitivity. Br J Anaesth 2021; 126:e27-e9.

85. Elst J, Sabato V, Mertens C, Garvey LH, Ebo DG. Association between mutated Masrelated $\mathrm{G}$ protein-coupled receptor- $\mathrm{X} 2$ and rocuronium-induced intraoperative anaphylaxis. Comment on Br J Anaesth 2020; 125: e446-e448. Br J Anaesth 2020; 125:e448-e50.

86. Alkanfari I, Gupta K, Jahan T, Ali H. Naturally Occurring Missense MRGPRX2 Variants Display Loss of Function Phenotype for Mast Cell Degranulation in Response to 
Substance P, Hemokinin-1, Human beta-Defensin-3, and Icatibant. J Immunol 2018; 201:343-9.

87. Ebo DG, Bridts $\mathrm{CH}$, Mertens $\mathrm{CH}$, Sabato V. Principles, potential, and limitations of ex vivo basophil activation by flow cytometry in allergology: A narrative review. J Allergy Clin Immunol 2020.

88. Dewachter P, Chollet-Martin S, Mouton-Faivre C, de Chaisemartin L, Nicaise-Roland P. Comparison of Basophil Activation Test and Skin Testing Performances in NMBA Allergy. J Allergy Clin Immunol Pract 2018.

89. Granger V, Taille C, Roach D, Letuve S, Dupin C, Hamidi F, et al. Circulating neutrophil and eosinophil extracellular traps are markers of severe asthma. Allergy 2020; 75:699702.

90. Gao Y, Han Y, Zhang X, Fei Q, Qi R, Hou R, et al. Penicillin causes non-allergic anaphylaxis by activating the contact system. Sci Rep 2020; 10:14160.

91. Hogwood J, Naggi A, Torri G, Page C, Rigsby P, Mulloy B, et al. The effect of increasing the sulfation level of chondroitin sulfate on anticoagulant specific activity and activation of the kinin system. PLoS One 2018; 13:e0193482.

92. Daguet A, Watier H. 2nd Charles Richet et Jules Hericourt workshop: therapeutic antibodies and anaphylaxis; May 31-June 1, 2011, Tours, France. MAbs 2011; 3:41721.

93. Steinke JW, Platts-Mills TA, Commins SP. The alpha-gal story: lessons learned from connecting the dots. J Allergy Clin Immunol 2015; 135:589-96; quiz 97.

94. Sanchez-Lopez J, Araujo G, Cardona V, Garcia-Moral A, Casas-Saucedo R, Guilarte M, et al. Food-dependent NSAID-induced hypersensitivity (FDNIH) reactions: Unraveling the clinical features and risk factors. Allergy 2020.

95. Fernandez J, Ruano-Zaragoza M, Blanca-Lopez N. Omalizumab and other biologics in drug desensitization. Curr Opin Allergy Clin Immunol 2020; 20:333-7.

96. Orengo JM, Radin AR, Kamat V, Badithe A, Ben LH, Bennett BL, et al. Treating cat allergy with monoclonal IgG antibodies that bind allergen and prevent IgE engagement. Nat Commun 2018; 9:1421.

97. Vultaggio A, Matucci A, Nencini F, Bormioli S, Vivarelli E, Maggi E. Mechanisms of Drug Desensitization: Not Only Mast Cells. Front Pharmacol 2020; 11:590991.

98. McDonnell NJ, Pavy TJ, Green LK, Platt PR. Sugammadex in the management of rocuronium-induced anaphylaxis. Br J Anaesth 2010; 106:199-201.

99. Leysen J, Bridts CH, De Clerck LS, Ebo DG. Rocuronium-induced anaphylaxis is probably not mitigated by sugammadex: evidence from an in vitro experiment. Anaesthesia 2011; 66:526-7.

100. Raft J, Leclercq $M$, Longrois $D$, Meistelman C. [Fast recovery of haemodynamic and ventilatory functions after sugammadex bolus following rocuronium-induced anaphylactic shock refractory to conventional treatment]. Ann Fr Anesth Reanim 2012; 31:158-61.

101. Spoerl D, D'Incau S, Roux-Lombard P, Harr T, Czarnetzki C. Non-IgE-Dependent Hypersensitivity to Rocuronium Reversed by Sugammadex: Report of Three Cases and Hypothesis on the Underlying Mechanism. Int Arch Allergy Immunol 2016; 169:25662.

102. Savic L, Savic S, Hopkins PM. Anaphylaxis to sugammadex. Anaesth Intensive Care 2014; 42:7-9. 
103. Ebo DG, Baldo BA, Van Gasse AL, Mertens C, Elst J, Sermeus L, et al. Anaphylaxis to sugammadex-rocuronium inclusion complex: An IgE-mediated reaction due to allergenic changes at the sugammadex primary rim. J Allergy Clin Immunol Pract 2020; 8:1410-5 e3.

104. Orihara M, Takazawa T, Horiuchi T, Sakamoto S, Nagumo K, Tomita Y, et al. Comparison of incidence of anaphylaxis between sugammadex and neostigmine: a retrospective multicentre observational study. Br J Anaesth 2020; 124:154-63. 


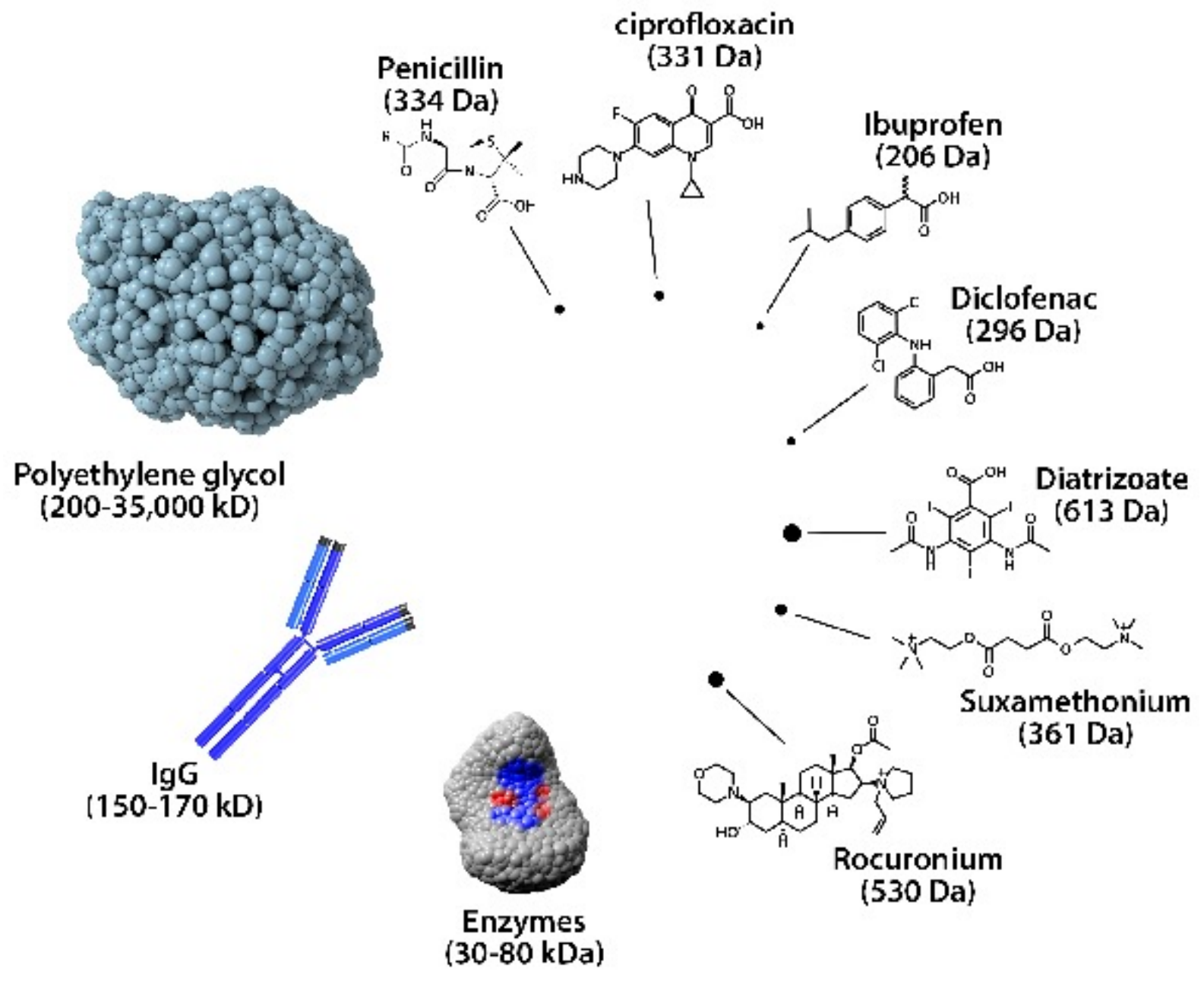
(30-80 kDa)

743 Figure 1. Relative drug sizes implicated in drug-induced anaphylaxis: size does not

744 matter. Schematic representations of poly ethylene glycol (Image Credit:

745 StudioMolekuul/Shutterstock.com), IgG, enzyme (Image credit; PDB 9LYZ), and chemical

746 structures of indicated drugs and contrast agents. Dots represent the relative size of the depicted

747 small molecules $(<1 \mathrm{kDa})$ compared to those of PEG, IgG and enzymes. 


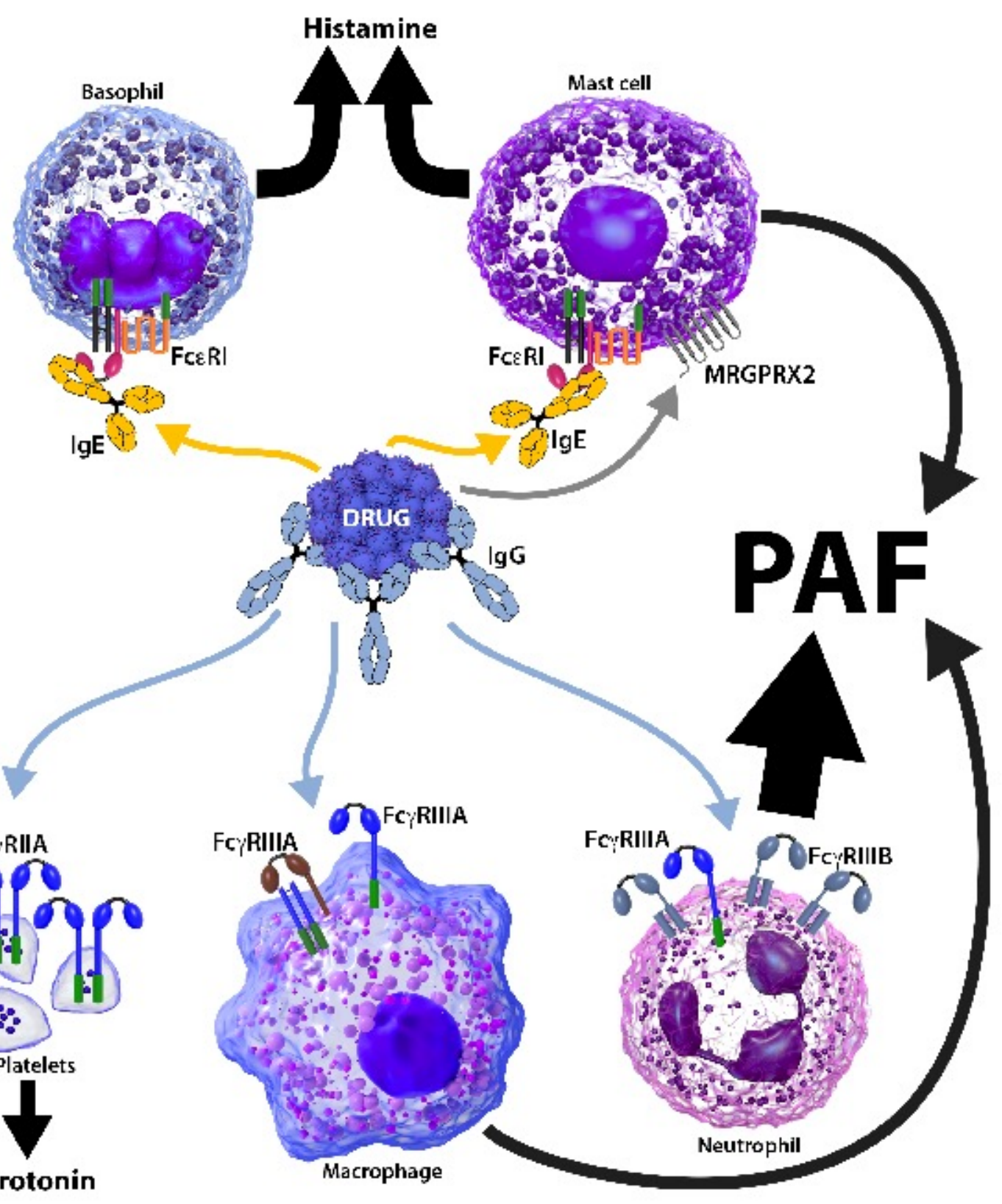

751 Figure 2. Potential pathways in drug-induced anaphylaxis. Once administrated a drug can

752 be bound by (a) drug-specific IgE antibodies, pre-bound on their high-affinity IgE receptor 753 (FceRI)-expressing mast cells and basophils, leading to their release of anaphylactogenic 754 mediators, histamine and to some extent PAF (Note: human mast cells are thought to make little or no serotonin); (b) drug-specific IgG antibodies, forming drug-IgG immune complexes that can bind to their low-affinity IgG receptor $(\mathrm{Fc} \gamma \mathrm{R})$-expressing neutrophils (e.g. Fc $\gamma$ RIIA and

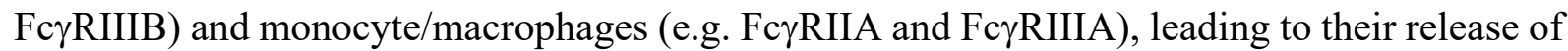
PAF, and to FcyRIIA-platelets leading to their release of serotonin; (c) mast cell-expressed MRGPRX2 if that drug has affinity for this receptor, leading to mast cell degranulation and histamine and PAF release. The thickness of the green-colored arrows represent their contribution to the indicated mediator release. 


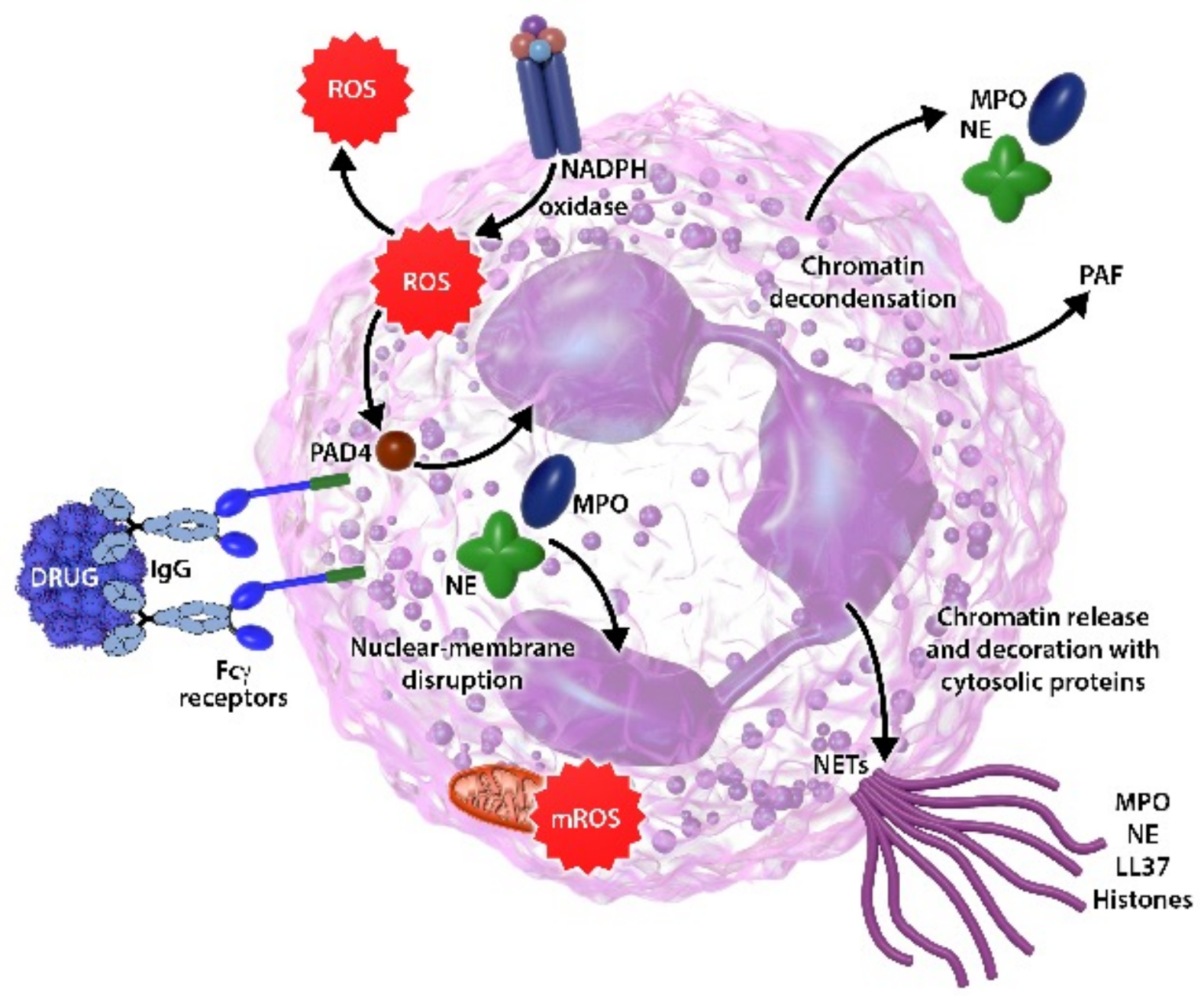

764 Figure 3. Mechanisms of IgG-induced neutrophil activation during drug anaphylaxis. The classical and historical pathway of anaphylaxis is based on mediator release by mast cells and basophils activated by the engagement of FceRI after their interaction with a drug/anti-drug IgE immune complex (IC). A second pathway was recently demonstrated both in mice and human. The drug can react with specific IgG and form an IC that binds to several Fc $\gamma$ Rs at the neutrophil surface and activate the cell. In addition to reactive oxygen species (ROS) and proteases release such as neutrophil elastase (NE) and myeloperoxidase (MPO), neutrophils release platelet activating factor (PAF) and neutrophil extracellular traps (NETs), also involved in anaphylaxis clinical manifestations. The release of NETs is the consequence of ROS production, in particular due to mitochondrial-derived ROS (mROS) production and peptidyl arginase deiminase 4 (PAD4) activation leading to chromatin decondensation, nuclear membrane disruption and chromatin extracellular release. 